\title{
A relevância de um ecossistema tecnológico no enfrentamento à Covid-19 no Sistema Único de Saúde: o caso do Rio Grande do Norte, Brasil
}

\author{
The relevance a technology ecosystem in the Brazilian National \\ Health Service's Covid-19 response: the case of Rio Grande \\ do Norte, Brazil
}

\author{
Ricardo Alexsandro de Medeiros Valentim (https://orcid.org/0000-0002-9216-8593) ${ }^{1}$ \\ Thaisa Santos Lima (https://orcid.org/0000-0001-8276-4124) ${ }^{2}$ \\ Lyane Ramalho Cortez (https://orcid.org/0000-0002-5096-9800) ${ }^{3}$ \\ Daniele Montenegro da Silva Barros (https://orcid.org/0000-0001-5037-1545) ${ }^{1}$ \\ Rodrigo Dantas da Silva (https://orcid.org/0000-0002-2549-2414) ${ }^{1}$ \\ Jailton Carlos de Paiva (https://orcid.org/0000-0002-2080-9945) ${ }^{4}$ \\ Karilany Dantas Coutinho (https://orcid.org/0000-0002-2051-8611) ${ }^{1}$ \\ Philippi Sedir Grilo de Morais (https://orcid.org/0000-0002-0636-7562) ${ }^{5}$ \\ Juciano de Sousa Lacerda (https://orcid.org/0000-0002-0876-377X) ${ }^{6}$ \\ Fernando Rocha de André (https://orcid.org/0000-0002-9459-6065) ${ }^{7}$
}

${ }^{1}$ Laboratório de Inovação

Tecnológica em Saúde

(LAIS), Universidade

Federal do Rio Grande do

Norte (UFRN). Av. Nilo

Peçanha 620, Petrópolis.

59012-300 Natal RN

Brasil. ricardo.valentim@

lais.huol.ufrn.br

${ }^{2}$ Ministério da Saúde.

Brasília DF Brasil.

${ }^{3}$ Departamento de Saúde

Coletiva, UFRN. Natal RN

Brasil.

${ }^{4}$ Instituto Federal de

Educação, Ciência e

Tecnologia do Rio Grande

do Norte. Natal RN Brasil.

${ }^{5}$ Programa de Pós-

Graduação em Engenharia

Elétrica e de Computação,

UFRN. Natal RN Brasil.

${ }^{6}$ Programa de Pós-

Graduação em Estudos da

Mídia, UFRN. Natal RN

Brasil.

${ }^{7}$ Ministério Público Federal

do Rio Grande do Norte.

Natal RN Brasil.

\begin{abstract}
Technological advances play an undeniable role in strengthening health systems. With regard to digital technologies, information systems and the analysis of health data are playing a growing role in health surveillance and preparing for and responding to disease outbreaks, the theme addressed by this article within the context of the Covid-19 pandemic in the State of Rio Grande do Norte. This study departs from the assumption that digital health interventions can increase Covid-19 response capacity. We developed a technology ecosystem that integrates different information systems to meet the needs outlined in international regulations governing the response to the pandemic. In addition to the main elements of the ecosystem, this article describes the application of this instrument by different institutional actors. The main decision making tool used in the state government's Covid-19 response, the ecosystem is a model for digital health interventions in Brazil's national health service. This experience in Rio Grande do Norte brings together elements that can contribute to studies investigating the resilience of health systems and analyzing health policies in emergency situations.
\end{abstract}

Key words Coronavirus Infections, Software, Technology, Technological Development and Innovation Projects, Epidemiological Surveillance, Health Care
Resumo É inegável o papel dos avanços tecnológicos para o fortalecimento da saúde. No tocante às tecnologias digitais, trata do uso crescente dos sistemas de informação e análise de dados em saúde nas ações de preparo, vigilância e resposta a surtos epidemiológicos, tema abordado neste artigo no contexto da pandemia provocada pelo vírus Sars-CoV-2 no estado do Rio Grande do Norte. Este estudo parte do pressuposto de que é possivel potencializar a gestão da resposta à Covid-19 por meio da saúde digital. Assim, a pesquisa desenvolveu um Ecossistema tecnológico que integra diferentes sistemas de informação para atender as necessidades previstas nas normativas internacionais frente à pandemia. Este artigo descreve, além do Ecossistema e sua estrutura, um conjunto de análises sobre a aplicação desse dispositivo por diversos atores institucionais. O Ecossistema foi a principal ferramenta em uso no estado para o processo decisório em resposta à Covid-19, sendo um modelo para a intervenção de saúde digital no Sistema Único de Saúde. A experiência do Rio Grande do Norte reúne, portanto, elementos que contribuem para os estudos sobre resiliência de sistemas e análises de políticas públicas em saúde em situações de emergência.

Palavras-chave Infecções por Coronavírus, Software, Tecnologia, Projetos de Desenvolvimento Tecnológico e Inovação, Vigilância Epidemiológica, Atenção à Saúde 


\section{Introdução}

É inegável o papel dos avanços tecnológicos para o fortalecimento da saúde humana: a descoberta da penicilina e das vacinas e o uso da imagem de ressonância magnética evidenciam que a ciência, a pesquisa e a tecnologia ampliaram as fronteiras do conhecimento e os saberes em saúde. No tocante às tecnologias digitais, pode-se mencionar o uso crescente dos sistemas de informação e a análise de dados em saúde nas ações de preparo, vigilância e resposta a surtos epidemiológicos, tema que será abordado neste artigo, no contexto da pandemia provocada pelo vírus Sars-CoV-2 ${ }^{1}$ no estado do Rio Grande do Norte (RN), Brasil, no ano de 2020. O novo coronavírus foi identificado na cidade de Wuhan, na China, após surto de pneumonia, no final de dezembro de 2019, tendo sido nomeado como causador da doença Covid-19'.

De acordo com a Organização Mundial de Saúde $(\mathrm{OMS})^{2}$, os países devem aproveitar o poder das tecnologias digitais para a implementação de políticas que garantam o acesso e a cobertura universal e reduzam iniquidades em saúde, portanto, promovendo mais sinergia para o alcance de objetivos globais. Ao mesmo tempo, se de um lado o desenvolvimento e os avanços tecnológicos são constantes e irrefreáveis pela sua própria natureza; de outro, eles tensionam os sistemas de saúde na sua missão. Nesse sentido, estudos sobre a utilização das tecnologias digitais pelos sistemas de saúde durante o enfrentamento da pandemia da Covid-19 ajudarão a responder a questões relativas à capacidade de resposta desses sistemas às situações de emergência de importância internacional, ao mesmo tempo que apontam caminhos para o fortalecimento do preparo, da vigilância e da resposta a situações futuras.

Em 30 de janeiro de 2020, a OMS declarou o nível mais alto de alerta global de saúde, previsto no Regulamento Sanitário Internacional (RSI) ${ }^{3,4}$, o chamado estado de Emergência de Saúde Pública de Importância Internacional (ESPII), em decorrência da epidemia da Covid-19. Foi a sexta vez, desde a aprovação do RSI, na ocasião da $58^{a}$ Assembleia Mundial de Saúde, em $2005^{5}$, que uma ESPII é declarada pela OMS na história da saúde global. Após 11 dias, seria caracterizada a pandemia. Diante do anúncio, as negociações da bolsa de valores foram interrompidas pela segunda vez desde a descoberta do novo coronavírus, fenômeno que não era observado desde a crise financeira de 2007/2008, e que, em 2020, ocasionou a perda de trilhões de dólares em todo o mundo, sinalizando, assim, que a nova doença tanto mata como pode paralisar a economia, devido às medidas de mitigação, como distanciamento, confinamento, quarentena e lockdown ${ }^{6}$.

A esse respeito, Lima et al. ${ }^{7}$ avaliam que a pandemia da Covid-19 potencializou tensões que são próprias das organizações sociais do mundo atual, um mundo que, apesar de "globalizado nas trocas econômicas" e "interconectado digitalmente", ainda é bastante "vulnerável à ocorrência e à disseminação global de doenças tanto conhecidas como novas". Para esses autores, o mundo se modernizou e se globalizou, mas também se tornou favorável às epidemias pela facilitação de circulação das pessoas e mercadorias entre os continentes e pelo uso do meio ambiente e da natureza de forma quase predatória, não sustentável. Desde março de 2020, os países mobilizam esforços para atender às recomendações da OMS e superar fraquezas evidenciadas na medida em que aumenta a mortalidade pela Covid-19. Nesse processo, e sobretudo pelo entendimento de que a vivência de uma pandemia pode ser considerada um fenômeno multidimensional (biológico, ambiental e social, com implicações políticas e econômicas), é que Lima et al. ${ }^{7}$ observam que a resposta global à Covid-19 é o resultado da acumulação de aprendizados da humanidade em seu percurso de enfrentamento das doenças, muitas vezes, combinando tecnologias.

No presente estudo, parte-se do pressuposto de que é possível potencializar a capacidade de gestão da resposta à Covid-19 no sistema de saúde do RN, por meio da utilização de um Ecossistema tecnológico customizado e guiado por protocolos de integração e interoperabilidade. Tais fatores colocam esse dispositivo em consonância com as recomendações e perspectivas da Política Nacional de Informação e Informática em Saúde (PNIIS) do Ministério da Saúde ${ }^{8}$, para integrar diferentes sistemas de informação e atender oportunamente as necessidades previstas nas normativas nacionais e internacionais. Além disso, o Ecossistema busca promover a produção, a utilização e a sistematização da informação em saúde no intuito de beneficiar usuários, profissionais, gestores, prestadores de serviços de saúde, instituições de ensino e pesquisa e a sociedade civil organizada ${ }^{8}$.

Para este estudo, foram eleitas as seguintes questões norteadoras: 1) como um Ecossistema tecnológico pode auxiliar na resposta à epidemia da Covid-19 no RN, Brasil?; 2) quais os critérios para customização da ferramenta no RN?; e 3) quais as contribuições da experiência para 
o fortalecimento do preparo, da vigilância e da resposta no SUS? Como objetivos, destacamse: descrever e analisar a implementação de um Ecossistema tecnológico para controle da epidemia da Covid-19 no RN; e discutir a contribuição das tecnologias digitais para além dos seus aspectos tecnológicos e de inovação em saúde, nesse caso, como intervenções de saúde digital no SUS.

\section{Materiais e métodos}

A pesquisa teve seu início, efetivamente, com a publicação do decreto estadual que instituiu o Comitê Governamental de Gestão da Emergência $^{9}$ no RN para o enfrentamento da Covid-19. Trata-se de uma pesquisa aplicada de natureza transdisciplinar, cujo objeto foi executado por meio de estudos, desenvolvimentos, adequações e aprimoramentos, os quais foram implementados durante a implantação de um Ecossistema tecnológico para o enfrentamento da epidemia de Covid-19 no estado do Rio Grande do Norte (RN). Então, pela natureza do objeto, das questões norteadoras da investigação e da necessidade de responder oportunamente à crise sanitária em curso, optou-se pela utilização do método pesquisa-ação, como conceituado por Tripp ${ }^{10}$. Para o autor, a pesquisa-ação é executada em ciclos de "aprimoramento de práticas" que dependem da sistematização do trabalho em dois campos: "o da prática e o da pesquisa a respeito desta prática"10.

Com base no exposto, o Ecossistema tecnológico foi desenvolvido em quatro fases, a saber: planejamento, desenvolvimento, avaliação e monitoramento. As fases foram executadas de forma cíclica e espiralar, ou seja, de modo sequencial, uma após a outra, sempre que um novo ciclo se iniciava ${ }^{11}$. Cada ciclo era executado em uma ou duas semanas, a depender das demandas que, muitas vezes, eram mutáveis e imprevisíveis, sempre de acordo com a urgência e nos tempos necessários a cada resposta (deadline). Esse modelo cíclico permitiu que o desenvolvimento do Ecossistema seguisse um curso no qual a produção das soluções passava por um processo de melhoria contínua, e mais flexível às mudanças ${ }^{11,12}$. Portanto, considerou-se o modelo adequado às necessidades do estado, naquele momento de enfrentamento à Covid-19. Conhecido também como modelo iterativo e incremental ${ }^{13}$ na área de Sistema de Informação em Saúde ${ }^{13}$, sua aplicação permitiu que as atividades fossem executadas nas dimensões da prática e da investigação de forma orgânica ao método de pesquisa escolhido.

Ao mesmo tempo, o objeto da pesquisa era um problema de ordem multidimensional, e que exigia uma atuação transdisciplinar, portanto, era necessário aplicar uma metodologia ágil de desenvolvimento de tecnologias que pudesse responder mais rapidamente às demandas impostas pela crise sanitária da Covid-19. Por isso, o desenvolvimento do Ecossistema foi centrado no framework Scrum ${ }^{14,15}$, uma vez que este é adequado ao modelo cíclico e espiralar, consoante a metodologia definida de pesquisa-ação ${ }^{16}$.

Todavia, além dessa tipificação metodológica, foi desenvolvido um estudo de caso ${ }^{17,18}$ sobre a análise do Ecossistema frente à crise sanitária no $\mathrm{RN}$, que é transversalmente um estudo social na área da saúde pública. Nessa análise, optouse pela abordagem de Goldenberg ${ }^{17}$ e Yin $^{18}$, cuja compreensão se dá em torno de captar as características de uma unidade social escolhida, o caso, e apresentar com rigor os dados empíricos dele coletados a partir de perguntas precisas e focadas em fatos contemporâneos ${ }^{17,18}$.

O estudo de caso foi centrado em explorar e analisar ações que extrapolavam o planejamento e o desenvolvimento do Ecossistema e que foram articuladas ao desenho da pesquisa-ação por meio de ações de cooperação técnica entre diversas instituições do RN. Isso porque foi preciso viabilizar não somente o desenvolvimento de um Ecossistema mas também o uso de novas tecnologias que implicaram efetivamente uma mudança nos processos de trabalho das instituições envolvidas. Desse modo, a análise dos resultados dessas articulações de cooperação técnica, bem como dos instrumentos produzidos na resposta à epidemia da Covid-19, foi guiada por um estudo de caso.

Para tanto, os dados produzidos sobre a utilização do Ecossistema foram analisados à luz de conceitos dos campos de sistemas e serviços de saúde e de análise de políticas públicas, especialmente a de "formação de agenda governamental", do modelo teórico de John Kingdon ${ }^{19}$, por contemplar análises sobre os processos de decisão e reconhecimento de determinado tema ou problema como prioritário na agenda pública ${ }^{19}$. As fontes primárias consideradas foram documentos, atas de reuniões, publicações oficiais do Governo do Estado e notícias publicadas sobre o objeto pela imprensa local. 


\section{Resultados}

O RN tem um Índice de Desenvolvimento Humano (IDH) de 0,684. Pelo último censo, de 2010, a população é estimada em 3.168 .027 pessoas. Possui 167 municípios divididos em oito regiões de saúde, das quais, as mais afetadas foram a sétima (ou Metropolitana) e a segunda (ou Oeste), esta última faz fronteira com o estado do Ceará. Ambas possuem as maiores populações, os principais fluxos e a maior complexidade de rede assistencial de saúde do estado.

Quanto à Covid-19, o primeiro Boletim Epidemiológico (BE) do RN foi publicado pela Secretaria de Estado de Saúde Pública (SESAP/ RN) em 28 de fevereiro de 2020, quando o estado apresentava oito notificações classificadas pelo Ministério da Saúde (MS) como casos suspeitos. Em 2 de março, o segundo BE, ainda sem caso confirmado, mostrava concentração dos casos suspeitos na 7a Região, principalmente no município de Natal. Essa característica apresentada no início da epidemia marcou todo o seu curso e ditou o processo decisório dos governos estadual e municipal. O primeiro caso confirmado no BE é de 13 de março e o primeiro óbito é de 29 de março. Ao final de julho, havia 58.132 casos confirmados e 2.019 óbitos distribuídos nas oito regiões, sendo a maior prevalência na $7^{\mathrm{a}}$ e na $2^{\mathrm{a}}$ Região $0^{20}$.

Do ponto de vista do preparo, da vigilância e da resposta, o RN foi um dos primeiros estados do Nordeste a criar um Plano Estadual de Contingência $(\mathrm{PEC})^{21}$, com vista à organização da rede assistencial e à integralidade das ações de vigilância e resposta. O RN seguiu as orientações da OMS, a Lei Federal no $13.979^{22}$ e a Portaria no 356 do $\mathrm{MS}^{23}$, além de contemplar a criação de um comitê gestor formado por representantes da administração estadual, coordenado diretamente pela governadoria; e um comitê de especialistas, composto por cientistas com um papel consultivo, para subsidiar a tomada de decisão. O PEC atual encontra-se em sua quarta versão.

Quanto aos seus principais direcionamentos, na primeira versão, o PEC adotou hospitais para leitos Covid-19 em três regiões $\left(7^{\mathrm{a}}, 4^{\mathrm{a}}\right.$ e $\left.2^{\mathrm{a}}\right)$, considerando-as polos geográficos estratégicos, num momento que o RN estava com curva ascendente de número de casos. Além disso, observou-se, em paralelo, a expansão e a abertura gradual de leitos críticos e de retaguarda para todo o estado, com ênfase naqueles locais onde os indicadores epidemiológicos sinalizavam que havia uma tendência ao "colapso" do sistema de saúde local. Na ocasião, vislumbrava-se a possibilidade de interiorização do vírus para os municípios das regiões mais centrais do estado ${ }^{24}$. Ao final de março, o RN tinha efetivamente pouco mais de 100 leitos SUS para a Covid-19, concentrados nessas três Regiões de Saúde; já ao final de julho, o SUS do RN oferecia um total de 655 leitos exclusivos para a Covid-19.

Nessa conjuntura, é importante mencionar as relações de cooperação que se estabeleceram entre algumas instituições do RN que, de forma organizada e sistematizada, atuaram em sinergia, com o objetivo de prover resposta à crise sanitária, essencialmente na dimensão da gestão, da transparência e do controle social. Pode-se afirmar que tanto o Ecossistema como as intervenções que foram derivadas de sua implantação no território são resultantes do processo cooperativo interinstitucional. No âmbito das cooperações estabelecidas, cabe destacar que o Laboratório de Inovação Tecnológica em Saúde (LAIS) da Universidade Federal do Rio Grande do Norte (UFRN), o Núcleo de Estudos de Saúde Coletiva da UFRN (NESC), o Núcleo Avançado de Inovação Tecnológica (NAVI) do Instituto Federal de Educação, Ciência e Tecnologia do Rio Grande do Norte (IFRN) e o corpo executivo da Secretaria de Estado de Saúde Pública (SESAP/RN) e da Secretaria Municipal de Saúde de Natal (SMS/ Natal) foram responsáveis pela execução técnica e científica do Ecossistema (concepção, elaboração, desenvolvimento e implantação).

Ao mesmo tempo, esse processo induziu o engajamento gradual das autoridades do estado (adesão ao uso das tecnologias), assim como houve ampliação da transparência e do controle social sobre a divulgação dos dados da Covid-19 na imprensa local. Isso porque o desenvolvimento do Ecossistema também teve como propósito qualificar a informação e mitigar os efeitos da infodemia ${ }^{24}$. Nesse cenário, é importante ressaltar a participação e a incorporação de outros atores institucionais no processo cooperativo, como o Ministério Público Federal (MPF/RN) e o Estadual (MPRN). Tais atores participaram essencialmente da elaboração de recomendações para o uso das tecnologias presentes no Ecossistema, ao mesmo tempo que utilizaram dados extraídos desse dispositivo nas suas análises e propostas de aperfeiçoamento do sistema de saúde do RN frente à crise sanitária de Covid-19. Esse é um dos resultados importantes da cooperação técnica, tanto pela efetiva colaboração para a resposta em saúde pública como pela promoção do engajamento para o uso das tecnologias disponibilizadas pelo Ecossistema para o RN, e também pela 
indução do controle social no estado. Sem isso, teria sido mais difícil romper a "inércia" da resistência dos atores governamentais do estado e dos municípios para o uso de novas tecnologias que impactam na mudança de processos de trabalho.

\section{O Ecossistema para o enfrentamento da Covid-19 no RN/BR}

A construção do Ecossistema Tecnológico do RN teve como paradigma a integração de funcionalidades da gestão dos serviços do SUS, com os aspectos propostos pela OMS, tanto no modelo de gestão dos centros de operações em emergências de saúde pública ${ }^{25}$ como na estratégia global para resposta à Covid-1926. Ou seja, o Ecossistema reúne e adapta as principais diretrizes globais numa única ferramenta de gestão, com o propósito de subsidiar a tomada de decisão, a coordenação e o planejamento da resposta à emergência. Ele também se articula com o PNIIS para resolver a falta de padronização e, consequentemente, de integração e interoperabilidade que permeia parte dos sistemas de informação em saúde no Brasil. "Cabe destacar ainda que o alcance da interoperabilidade dos sistemas de informação em saúde é condição central desta Politica, tendo em vista que só a partir desta integração será possível amparar um processo decisório coerente com as reais necessidades da população" ${ }^{10}$. Nesse ponto, toda a arquitetura tecnológica do Ecossistema foi dirigida por protocolos nacionais e internacionais de interoperabilidade, cujo propósito foi garantir um alto índice de integração com as tecnologias já em execução no RN e no Brasil, bem como com tecnologias futuras. Nesse sentido e em sinergia com as demandas e necessidades do RN para o enfrentamento à Covid-19, o Ecossistema foi integrado aos seguintes sistemas de informação em saúde do Ministério da Saúde: eSUS Notifica, SIVEP-Gripe, Cartão SUS e CNES.

Esse Ecossistema é composto por 13 subsistemas ou ferramentas para os serviços, alguns deles já existentes no SUS, e outros que foram oportunamente desenvolvidos pelo LAIS/UFRN como soluções para fortalecer a integralidade da resposta do estado e sua conexão com alguns dos principais aspectos propostos pela OMS: mobilização intersetorial; comunicação de riscos e participação comunitária; controle e prevenção de casos; e supressão da transmissão e da redução da mortalidade a partir da provisão de serviços de saúde oportunos e de qualidade.

A Figura 1 é a representação gráfica do Ecossistema. Escolheu-se o mapeamento em formato de mandala, por ser o que mais bem apresenta a dinâmica da articulação e da mobilidade entre os subsistemas (parte interna representada em fatias) e as dimensões globais que foram operacionalizadas na política pública estadual de resposta à Covid-19 (representadas nas bordas). Cabe destacar que essas dimensões atuam de forma transversal, portanto, são perpassadas por várias tecnologias e/ou processos dispostos na mandala. A simbologia adotada na Figura 1 pode ser observada também nas cores definidas para cada dimensão, as quais estão dispostas, respectivamente, na base de cada tecnologia e/ou processo, portanto, realça a transversalidade e a interseção entre esses estereótipos (dimensões e tecnologias).

As dimensões do Ecossistema são descritas como:

Comunicação e Participação Comunitária: apresentação proativa de informações à sociedade para reduzir confusões e prevenir a infode$\mathrm{mia}^{27}$, além de gerar mais confiança intersetorial e envolvimento comunitário.

Educação: formação humana em saúde para o preparo, a vigilância e a resposta do sistema de saúde estadual no enfrentamento à Covid-19 e para a promoção de resiliência.

Vigilância integral: produção de dados a partir da integração dos diferentes sistemas e dos serviços de saúde existentes, para fins de monitoramento, transparência e prevenção das doenças.

Monitoramento: apoio à tomada de decisão a partir de painéis de indicadores e análises integradas sobre o contexto epidemiológico, socioeconômico e de gestão dos serviços de saúde.

Atenção integral à saúde: fortalecimento das redes de atenção por meio do apoio tecnológico como suporte à continuidade da linha de cuidado, especialmente na Atenção Primária à Saúde (APS), até a rede hospitalar, com cuidados intensivos em saúde.

Rastreio e Manejo de Contatos: monitoramento de casos e respectivos contatos com avaliação de risco e orientações de medidas de saúde pública e de distanciamento físico.

Manutenção de serviços essenciais: acolhimento de profissionais de saúde como medida de prevenção à disseminação e à exposição de riscos, de recrutamento de voluntários e de preservação de serviços essenciais de APS.

Planejamento: fortalecimento de planos e protocolos para o manejo da resposta estadual durante a epidemia.

Regulação: ordenamento do acesso aos serviços de UTI mediados por tecnologia, a fim de 


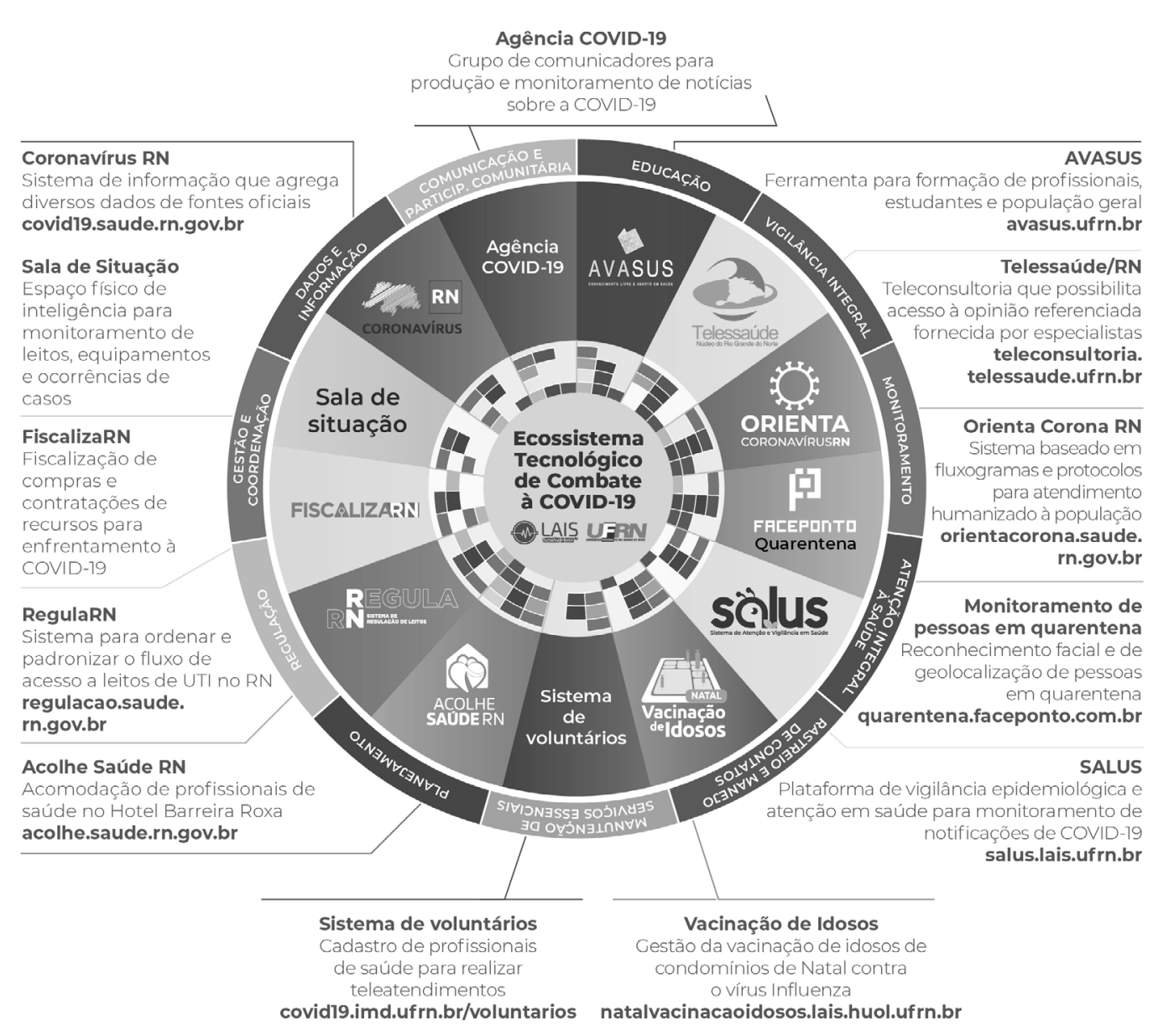

Figura 1. Ecossistema de resposta ao Covid-19 no Rio Grande do Norte.

Fonte: Elaborado pelos autores.

ampliar a transparência, melhorar a eficiência, fortalecer o controle social e aprimorar a resposta do estado à fiscalização pelos órgãos de controle.

Gestão e Coordenação: disponíveis nos níveis operacional, gerencial e estratégico.

Dados e Informação: disponibilidade, acessibilidade e qualidade guiadas pelos princípios da transparência e da qualificação dos dados e informação em todos os níveis de gestão.

Os sistemas e/ou processos são apresentados na parte interna da mandala e descritos no Quadro 1. Alguns deles estão sinalizados como âncoras na dinâmica do Ecossistema.

Assim, observa-se que o Ecossistema estabelece organicamente um processo sinérgico de retroalimentação entre as tecnologias desenvolvidas e as dimensões dispostas na mandala (processos de inputs e outputs). Nessa direção, possibilita-se que a gestão da saúde, tanto no estado como nos municípios, possa ativar pontos que são alimentados dinamicamente. Ao mesmo tempo, os dados e informações projetados para o público em tempo real também permitem que a sociedade, os gestores, e os órgãos de controle atuem de maneira mais qualificada no que diz respeito às questões mais urgentes.

A multidimensionalidade do Ecossistema o diferencia de outros trabalhos similares no mundo, porque estes estão mais centrados em painéis de monitoramento ou em aplicações específicas, seja para a vigilância, seja para a assistência. $\mathrm{O}$ Ecossistema para o enfrentamento à Covid-19 no $\mathrm{RN}$, diferentemente dos demais, tem uma abordagem integrada e transversal como objeto do seu desenvolvimento e aplicação no âmbito do SUS $^{28-37}$. 
Quadro 1. Descrição das Tecnologias e/ou processo que compõe o ecossistema.

\begin{tabular}{|c|c|}
\hline Título & Descriçãa \\
\hline Agência Covid-19* & $\begin{array}{l}\text { Processo de trabalho instituído por comunicadores com o propósito de fortalecer a comunicação } \\
\text { do setor saúde durante o enfrentamento da pandemia. Eixos norteadores: combater a infodemia, } \\
\text { esclarecer a população, produzir reportagens especiais, organizar coletivas e pautar a imprensa } \\
\text { sobre os temas relevantes de interesse público e fortalecer a comunicação pública e governamental } \\
\text { de forma transversal e com autonomia }\end{array}$ \\
\hline $\begin{array}{l}\text { Sala de Situação } \\
\text { https://portalcovid19. } \\
\text { saude.rn.gov.br/ }\end{array}$ & $\begin{array}{l}\text { Espaço físico de inteligência implantado na SESAP/RN em parceria com o LAIS, para } \\
\text { monitoramento de dados, análises e informação a partir do ecossistema, para subsidiar a gestão e o } \\
\text { processo decisório no estado }\end{array}$ \\
\hline $\begin{array}{l}\text { AVASUS* } \\
\text { https://avasus.ufrn.br/ }\end{array}$ & $\begin{array}{l}\text { Plataforma online que já é parte da cooperação do LAIS/UFRN com o MS e que se somou ao } \\
\text { ecossistema com propósito de escalar e capilarizar rapidamente o processo formativo no RN. Tal } \\
\text { processo foi aplicado tanto para os trabalhadores da saúde (qualificação da força de trabalho), } \\
\text { como também oferecido à população geral, que necessitava de informações qualificadas sobre o } \\
\text { vírus Sars-CoV-2 e sobre a própria doença Covid-19 }\end{array}$ \\
\hline $\begin{array}{l}\text { Telessaúde RN } \\
\text { http://www.telessaude. } \\
\text { ufrn.br/ }\end{array}$ & $\begin{array}{l}\text { Plataforma estadual que se somou aos esforços de enfrentamento à Covid-19, com o foco } \\
\text { principal na atenção prinárial, tendo como eixos de atuação: manejo clínico de pacientes, cuidado, } \\
\text { diagnóstico, acolhimento e redes de atenção }\end{array}$ \\
\hline $\begin{array}{l}\text { Orienta Coronavírus } \\
\text { RN } \\
\text { https://orientacorona. } \\
\text { sauden.gov.br/ }\end{array}$ & $\begin{array}{l}\text { Sistema de teleatendimento desenvolvido atendimento a população. O objetivo principal é oferecer } \\
\text { orientações e informações sobre a Covid-19 para o autocuidado do indivíduo em domicílio, } \\
\text { evitando a sobrecarga nos serviços de saúde }\end{array}$ \\
\hline $\begin{array}{l}\text { Faceponto: quarentena } \\
\text { https://quarentena. } \\
\text { faceponto.com.br/ }\end{array}$ & $\begin{array}{l}\text { Sistema de informação que atua integrado à plataforma Orienta Coronavírus RN. Tem função de } \\
\text { monitorar os pacientes em distanciamento físico }\end{array}$ \\
\hline $\begin{array}{l}\text { Salus } \\
\text { https://salus.lais.ufrn. } \\
\text { br }\end{array}$ & $\begin{array}{l}\text { Sistema desenvolvido para potencializar a integração entre a vigilância epidemiológica e à atenção } \\
\text { à saúde. Implantado no Departamento de Vigilância da Secretaria Municipal de Saúde de Natal/ } \\
\text { RN, tem como objetivo tratar e corrigir erros gerados pelos sistemas de notificação do MS, como o } \\
\text { e-SUS VE. Auxilia no monitoramento e no cuidado dos pacientes na atenção primária e nas redes } \\
\text { de atenção à saúde do município de Natal. Destaca-se que Natal detém mais de } 48 \% \text { de todos os } \\
\text { casos de Covid-19 do estado. O sistema foi essencial para automatização do trabalho, até então } \\
\text { manual, qualificando o tempo da equipe nas ações de vigilância integral }\end{array}$ \\
\hline $\begin{array}{l}\text { Vacinação Idosos } \\
\text { https:// } \\
\text { natalvacinacaoidosos. } \\
\text { lais.huol.ufrn.br/ }\end{array}$ & $\begin{array}{l}\text { Plataforma desenvolvida para fortalecer a política de proteção de idosos da Secretaria Municipal de } \\
\text { Saúde Natal/RN. Reúne o cadastro de idosos residentes em condomínios verticais para vacinação } \\
\text { da gripe em seus domicílios. Possibilitou o planejamento e a operação da vacinação em mais de } \\
6.034 \text { (seis mil e trinta e quatro) idosos em } 384 \text { condomínios do município de Natal-RN }\end{array}$ \\
\hline $\begin{array}{l}\text { Sistema de voluntários } \\
\text { https://covid19.imd. } \\
\text { ufrn.br/voluntarios/ }\end{array}$ & $\begin{array}{l}\text { Sistema de informação para recrutamento de força de trabalho em saúde para o enfrentamento da } \\
\text { pandemia }\end{array}$ \\
\hline $\begin{array}{l}\text { Acolhe RN } \\
\text { https://acolhe.saude. } \\
\text { rn.gov.br/ }\end{array}$ & $\begin{array}{l}\text { Projeto realizado em parceria com a Federação do Comércio de Bens, Serviços e Turismo do } \\
\text { Estado do Rio Grande do Norte (FECOMÉRCIO). A estrutura do Hotel Barreira Roxa foi utilizada } \\
\text { para hospedar servidores da saúde que comprovem conviver com pessoas do grupo de risco ou } \\
\text { que tenham pessoas infectadas na mesma residência. O sistema foi desenvolvido para gerenciar a } \\
\text { triagem e o tempo de permanência dos servidores no projeto }\end{array}$ \\
\hline $\begin{array}{l}\text { Regula } \mathrm{RN}^{*} \\
\text { https://regulacao.lais. } \\
\text { ufrn.br/sala-situacao/ } \\
\text { sala_publica/ }\end{array}$ & $\begin{array}{l}\text { Plataforma desenvolvida para gerenciar a regulação de leitos Covid-19 no estado do RN totalmente } \\
\text { integrada ao e-SUS Notifica, aspecto que solucionou o problema de retrabalho, qualificando a } \\
\text { informação e mantendo a integridade dos dados. Totalmente transparente, a plataforma ampliou o } \\
\text { controle social e o poder fiscalizatório, disciplinou o processo de regulação no estado e foi decisiva } \\
\text { para as tomadas de decisão relativas ao quantitativo de leitos Covid-19 no estado }\end{array}$ \\
\hline $\begin{array}{l}\text { Fiscaliza RN } \\
\text { https://fiscalizarn.lais. } \\
\text { ufrn.br/login }\end{array}$ & $\begin{array}{l}\text { Plataforma desenvolvida por meio de cooperação técnica-científica entre a LAIS/UFRN e o MPF/ } \\
\text { RN (GT Covid-19) para fiscalizar as contas públicas no que tange aos gastos realizados com } \\
\text { Covid-19 pelo governo do estado e todos os municípios do RN }\end{array}$ \\
\hline $\begin{array}{l}\text { Coronavírus } \mathrm{RN}^{\star} \\
\text { https://covid.lais.ufrn. } \\
\text { br/ }\end{array}$ & $\begin{array}{l}\text { Plataforma desenvolvida para funcionar como um painel de monitoramento online de } 149 \\
\text { indicadores sobre a Covid-19 no RN, que são atualizados no mínimo três vezes ao dia }\end{array}$ \\
\hline
\end{tabular}

${ }^{\star}$ Tecnologias ou processos âncoras do ecossistema. 


\section{Agência Covid-19}

No início da pandemia, um dos pontos consensuais no Comitê Científico da SESAP/RN foi a comunicação ${ }^{24,38}$. Nesse sentido, era necessário definir um fluxo de comunicação que qualificasse as informações fornecidas à população e ao poder público, para evitar a infodemia aguda, que era observada nacionalmente, a qual servia de agente de desarticulação entre os poderes e também era usada para confundir a população. Era preciso criar e estabelecer uma agenda sistemática para as estratégias da comunicação oficial do governo e pautar a imprensa local.

Nesse campo, há vários exemplos, que ganharam notoriedade na imprensa nacional e internacional, tais como: o negacionismo, que pregava que o novo coronavírus era somente uma "gripezinha"; soluções "milagrosas", como o uso da Ivermectina ou da Cloroquina; negligência quanto ao uso da máscara, pois era comum ver na imprensa líderes políticos, de envergadura nacional, promovendo aglomerações e andando sem máscara em vários lugares e até em estabelecimentos comerciais fechados.

Por sua vez, o Governo do RN não conseguiu lograr êxito ao tentar contratar uma agência de publicidade que pudesse executar um plano de comunicação capaz de permear todos os níveis da sociedade ${ }^{39}$. Nesse contexto, na agenda de cooperação técnica do LAIS/UFRN com o governo, foi criada a Agência Covid-19, formada por mais de 20 comunicadores do $\mathrm{RN}$, entre jornalistas profissionais, pesquisadores doutores, doutorandos e mestrandos da área de mídia e graduandos em jornalismo, publicidade e audiovisual. Essa foi uma ação coordenada pelo LAIS/UFRN, em conjunto com pesquisadores do Departamento de Comunicação da UFRN e do Hiperlab da Universidade do Estado do Rio Grande do Norte (UERN). O objetivo da Agência Covid-19 foi o de pautar a grande imprensa local na busca de conteúdos qualificados e realmente de interesse público frente à pandemia e, dessa forma, mitigar os efeitos das fake news.

Além das coletivas de imprensa, foram produzidos diversos materiais, como: entrevistas, sugestões de pauta, reportagens, infográficos, podcasts, transmissões de vídeo e cards para redes sociais digitais. Até julho, a Agência Covid-19 havia realizado mais de 50 ações de comunicação nos seguintes eixos: vacinação e proteção aos idosos; distanciamento físico; uso de medicamentos sem evidências científicas; dados epidemiológicos; esclarecimento sobre o vírus; apresentação do Ecossistema tecnológico e de seus aplicativos e plataformas; organização de coletivas de imprensa com foco no jornalismo científico. Parte do material produzido pode ser acessado em https://lais.huol.ufrn.br/categoria/noticias/coronavirus/.

\section{AVASUS: Ambiente virtual de Aprendizagem do Sistema Único de Saúde (SUS)}

O AVASUS, que já é produto da cooperação técnica do LAIS/UFRN com o MS desde 2015, foi incluído no Ecossistema como instrumento mediador para a formação humana em saúde e também como um indutor do processo de resposta no estado. Com o AVASUS, o processo formativo para a Covid-19 foi realizado em um modelo totalmente mediado por tecnologia, o que contribuiu para a escalabilidade no processo de formação e para a diminuição da exposição dos cursistas ao vírus. Nesse contexto, foram disponibilizados 20 cursos em uma trilha formativa específica para a Covid-19: https://avasus.ufrn.br/ local/avasplugin/cursos/covid.php. Com exceção do primeiro curso, desenvolvido em parceria com a Organização Pan-americana de Saúde (OPAS) e com o MS, todos os demais foram elaborados de acordo com as demandas do território.

Nesse período, foram alcançadas marcas importantes, não somente no RN mas também em todo o país, e em parte do mundo. O Quadro 2 detalha alguns indicadores, os quais demonstram, de forma quantitativa, a escalabilidade que a adoção da mediação tecnológica (o AVASUS) promoveu para a formação em saúde. Cabe destacar que essa escalabilidade alcançada com o AVASUS, que é parte do Ecossistema, seria praticamente impossível de ser estabelecida caso o formato escolhido tivesse sido o presencial. Os resultados demonstrados no Quadro 2 tornam evidente a importância desse modelo formativo em situações de crise sanitária, como a vivenciada no RN, em virtude da Covid-19.

\section{RegulaRN}

No início da epidemia, era comum o tensionamento dos sistemas de saúde do mundo e de alguns estados brasileiros quanto ao oferecimento de leitos de terapia intensiva para o acesso oportuno dos pacientes infectados com o SarsCov-2. No RN, tornou-se urgente a revisão do planejamento e a logística de distribuição dessas unidades em todo o estado. 
Quadro 2.Números do processo formativo no AVASUS no enfrentamento a Covid-19.

\begin{tabular}{|l|r|}
\hline Número de alunos alcançados* $^{\star}$ & 121.193 \\
\hline Número total de inscrições alcançadas & 241.238 \\
\hline Média de alunos por curso & 12.064 \\
\hline Número de municípios alcançados no RN & 111 \\
\hline Número de alunos alcançados no RN & 24.315 \\
\hline Número de estado alcançados no Brasil & 27 \\
\hline Número de alunos alcançados no Brasil & 131.396 \\
\hline Número de pais alcançados & 55 \\
\hline Número de alunos estrangeiros alcançados & 2.014 \\
\hline $\begin{array}{l}\text { Número de cursos ofertados para o } \\
\text { enfrentamento a Covid-19 }\end{array}$ & 20 \\
\hline
\end{tabular}

Nota: ${ }^{*}$ A diferença entre alunos alcançados (usuários do AVASUS na Covid-19) e inscrições alcançadas (número de matrículas feitas em cursos do AVASUS na trilha formativa para Covid-19) é que um mesmo aluno pode fazer mais de um curso, por isso o comum é sempre ter um número de inscrições maior do que o número de alunos.

Fonte: Plataforma Coronavírus RN (acessada em até o dia 29 de novembro de 2020. Disponível em: https://covid.lais.ufrn. $\mathrm{br} /$ \#capacitados-em-covid19).

O RegulaRN foi desenvolvido para gerenciar a operacionalização do Complexo Estadual de Regulação (CER/RN) que trabalhava de forma manual. Naquele momento, os dados - como necessidade e disponibilidade de leitos, inclusive a previsão para abertura de novas unidades - eram imprescindíveis.

A primeira versão do RegulaRN começou a operar no final de abril e a implantação do sistema contou com o apoio do Ministério Público Federal (MPF/RN) e do Estado (MPRN), os quais recomendaram que o estado, os municípios e os prestadores utilizassem a plataforma integrando seus dados. A recomendação dos órgãos de controle induziu o engajamento de todos e tornou mais célere o processo de implantação do subsistema.

Uma das funcionalidades mais importantes do RegulaRN é a Sala de Situação. Trata-se de uma área pública, representada pela Figura 2, cujo propósito é dar ampla publicidade e transparência ao processo regulatório ${ }^{40}$. Destaca-se que os dados são apresentados e atualizados em tempo real, diante de uma dinâmica que varia ao longo de todo o dia.

Em pouco mais de 60 dias, a plataforma permitiu que o CER/RN encaminhasse mais de 3.700 pacientes com Covid-19 para leitos críticos ou clínicos. Dos que foram regulados, até o dia
22 de julho, 1.932 obtiveram alta por cura. A plataforma ainda permitiu registrar a implantação e monitorar todos os leitos SUS para Covid-19 no RN, sendo 301 leitos de UTI e 343 leitos clínicos, além de permitir a gestão da utilização de ventiladores.

\section{CoronavírusRN}

A plataforma CoronavírusRN, disponível em: https://covid.lais.ufrn.br/, é um ambiente de inteligência, com visão integral e intersetorial, concebido em consonância com as diretrizes do SUS e com base nos princípios da Política Nacional de Informação e Informática em Saúde (PNIIS) ${ }^{41}$. Para compor o painel de gestão da informação, foram selecionados 149 indicadores que são apresentados em formato de gráficos, tabelas, mapas, cenários e projeções, conforme Figura 3.

A Plataforma CoronavírusRN coleta informações de diversas fontes de dados dos municípios, do estado, do país ${ }^{42}$ e das redes sociais. Com isso, cumpre o papel de disponibilizar indicadores para a gestão pública, a população, a imprensa e também para os órgãos de controle, de forma ágil, centralizada, direcionada e aberta. A ferramenta colocou o $\mathrm{RN}$ em segundo lugar nacional em nível de transparência no enfrentamento à Covid-19, com 98 pontos. Tal resultado pode ser conferido pela Open Knowledge Brasil, tendo sido publicado no site Transparência Covid-1943.

\section{Salus}

O Salus é uma plataforma de vigilância epidemiológica e de monitoramento para a APS. Ele foi desenvolvido por meio de uma parceria com a Secretaria Municipal de Saúde (SMS) de Natal-RN, com o objetivo de qualificar os dados e integrar as ações de vigilância e atenção primária, além de corrigir inconsistências no envio de dados para o nível central, a partir de algoritmos inteligentes.

A plataforma foi adaptada para as necessidades locais, como a divisão de território por distritos sanitários, de modo que os estabelecimentos da APS podem monitorar diretamente os pacientes notificados que residem em seu raio de atuação no território. Para a vigilância, a plataforma gera indicadores locais e automatiza a consolidação de boletins epidemiológicos. A Figura 4 apresenta parte dos indicadores do Salus, incluindo mapas de calor nos bairros de Natal. O Salus, além de ser importante ferramenta de auxílio na tomada de decisão, articula a integra- 


\section{GुLAIS}
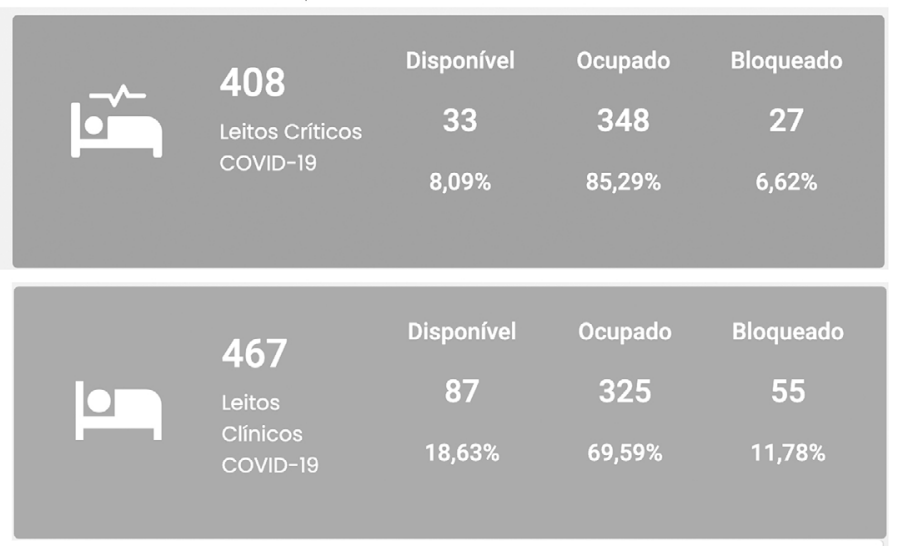

Rota das Regulações

Passe o mouse sobre os trajetos para mais detalhes. Dados dos últimos 7 (sete) dias.

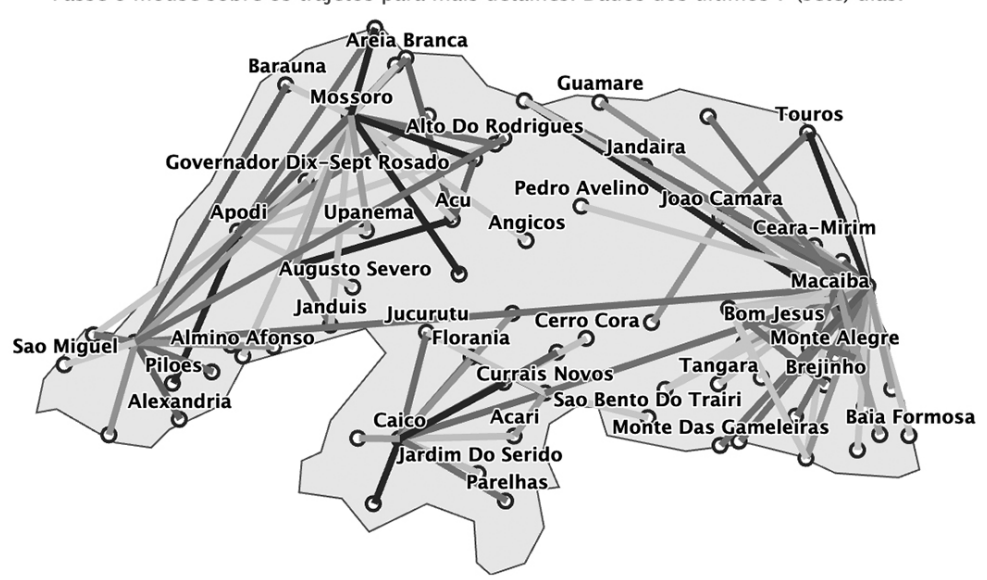

RegulaRN - SESA

\section{Pacientes na Lista de Regulação - RN}

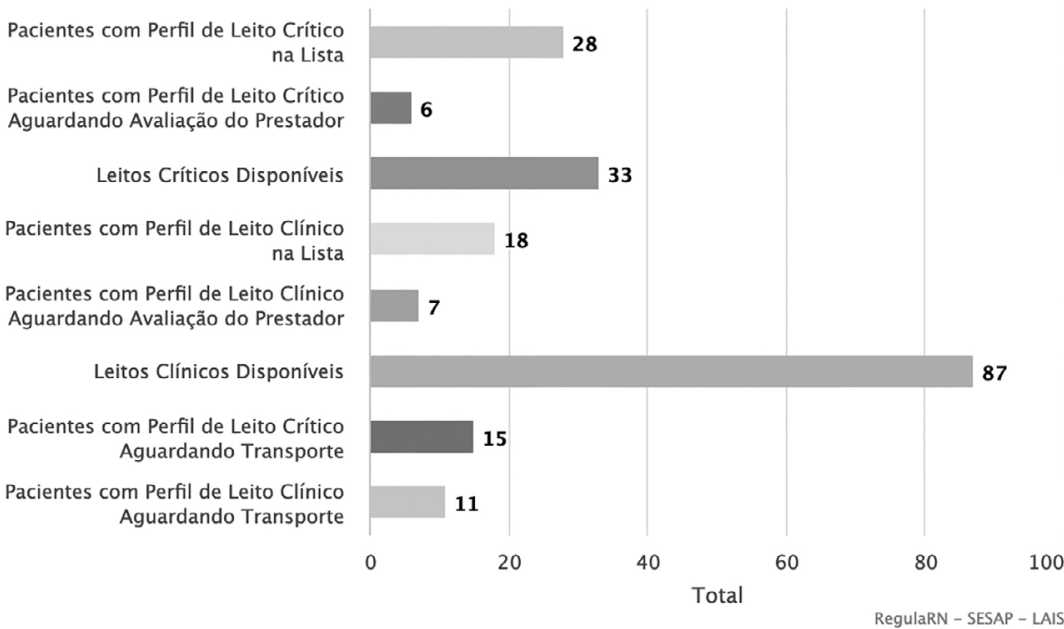

Figura 2. Sala de Situação do RegulaRN. 


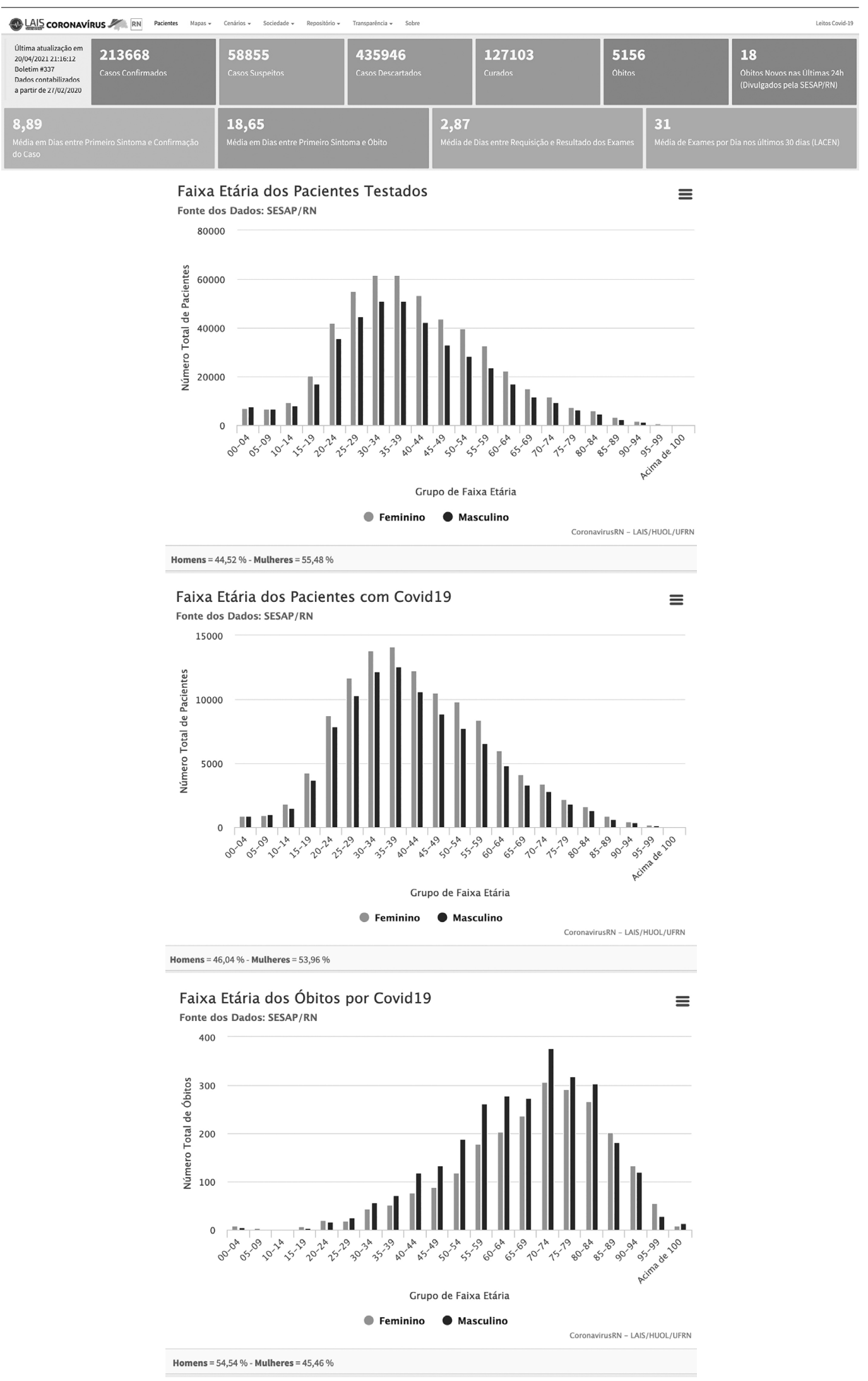

Figura 3. Dados da Sala de Situação mostrados na plataforma CoronavírusRN. 

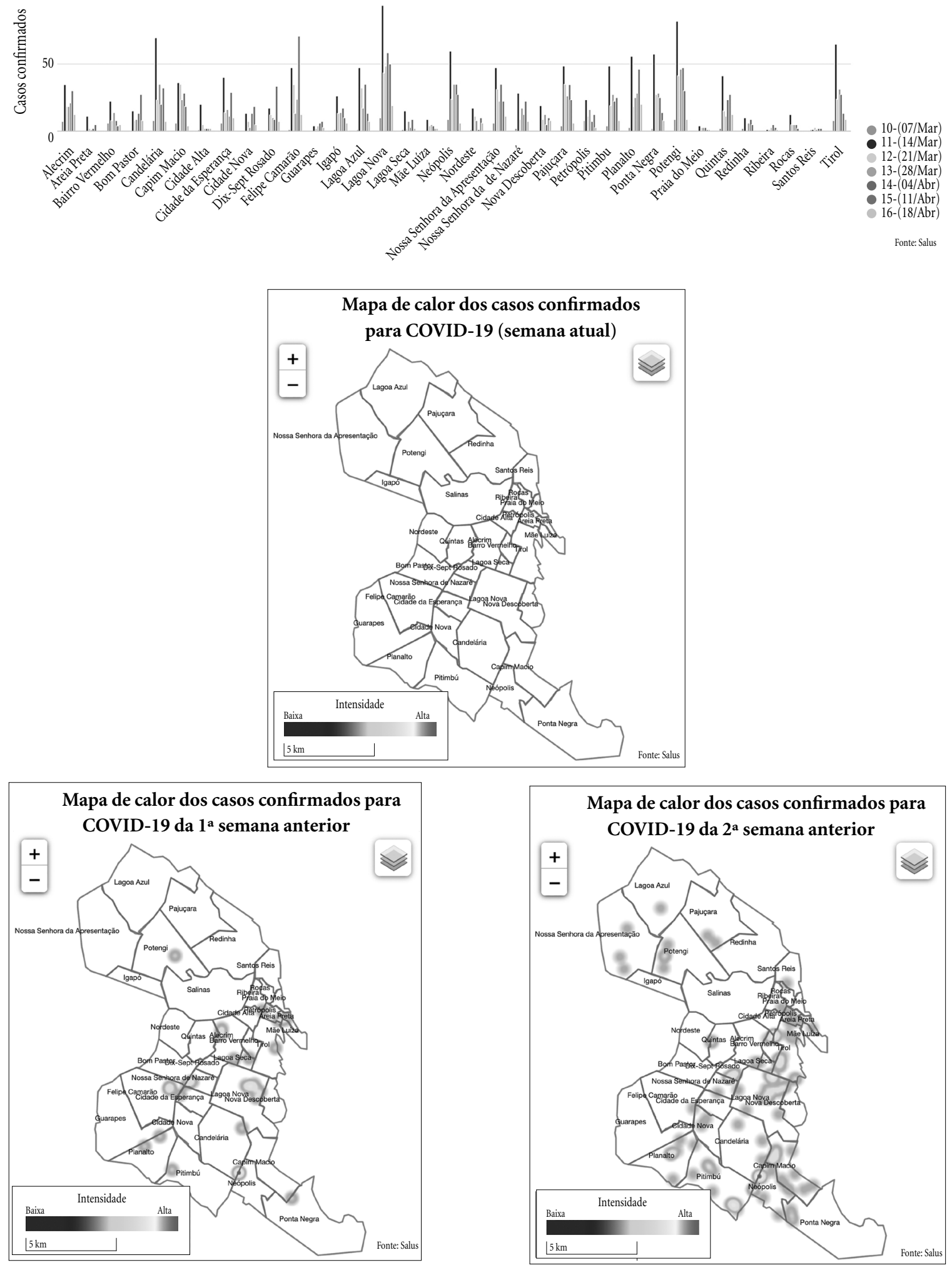

Figura 4. Indicadores apresentados na plataforma Salus. 
ção entre a vigilância e a APS, o que representa uma inovação singular para a saúde, pois essas são áreas comumente dicotômicas no Brasil ${ }^{44}$.

\section{Vacinação de Idosos}

O controle da vacinação de idosos para H1N1, por meio de um sistema específico, transcorreu no âmbito da cooperação da Secretaria Municipal de Saúde de Natal (SMS/Natal-RN). Na ocasião, era necessário mitigar as aglomerações e planejar a logística para vacinação, levando em conta a proteção ao deslocamento dos idosos, uma vez que estes são considerados população de alto risco para Covid-19. A solução tecnológica foi desenvolvida de maneira a mapear os condomínios residenciais e registrar os seus residentes idosos.

Nesse contexto, o sistema implementou um cadastro que deu capacidade à SMS/Natal-RN para o planejamento e a logística de mobilização das equipes de saúde para as intervenções de vacinação domiciliar ${ }^{45-49}$. "A campanha de vacinação contra gripe, realizada em condomínios de Natal, capital potiguar, terminou nesta sexta-feira (24). De acordo com a Secretaria Municipal de Saúde (SMS), foram vacinados contra influenza um total de 3.439 idosos em 390 condomínios da cidade. A iniciativa [...] foi desenvolvida para evitar aglomeração de idosos nos postos de vacina-

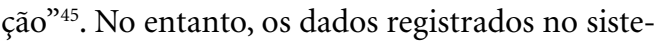
ma Natal Vacinação Idosos, mostram que foram autocadastrados 607 condomínios e 7.344 idosos. Esses dados diferem dos citados pela SMS/Natal $-\mathrm{RN}^{49}$, porque foram realizados autocadastros de condomínios e idosos em outros municípios da região metropolitana, os quais não fazem parte da sua cobertura vacinal.

\section{Orienta Coronavírus RN}

O sistema Orienta Coronavírus RN é uma ferramenta voltada para auxiliar a população para seu autocuidado, multiplicando ações de prevenção individuais e coletivas nos seus domicílios, bairros e comunidades. Com isso, contribui para mitigar a sobrecarga nos serviços de saúde. Os serviços disponíveis nessa ferramenta estão dispostos por dois níveis: autoatendimento e teleatendimento ${ }^{50}$. Os seus usuários também podem ser monitorados por meio do Faceponto Quarentena ou pelo Módulo de Monitoramento do Salus, quando houver recomendação pelas equipes de saúde. Nessa perspectiva, foram realizados mais de 7.000 atendimentos no Orienta
Coronavírus RN em todo o estado. Todavia, o monitoramento de mais 15.000 pacientes ocorreu efetivamente via Módulo de Monitoramento do Salus em detrimento do Faceponto Quarentena. Isso porque a SMS/Natal-RN, além de utilizar o Salus como ferramenta, também incluiu essa rotina em seus processos de trabalho, o que aumentou a adesão, o engajamento e a preferência por essa tecnologia em específico.

\section{Uso e aplicação do ecossistema na resposta à Covid-19 no $\mathrm{RN}$}

A partir do final de maio, já era possível verificar alguns resultados a respeito da utilização do Ecossistema nas ações de preparo, vigilância e resposta do $\mathrm{RN}$ à Covid-19, principalmente na tomada de decisão governamental. No repositório da Plataforma Coronavírus RN (https:// covid.lais.ufrn.br/\#documentos), observa-se a sistematização de alguns documentos técnicos providos pelo Ecossistema, assim como documentos de decisão do estado, distribuídos em função da data de sua publicação, do seu objeto, de instituições e setores que participaram do processo decisório no RN.

\section{Discussão}

O estudo demonstrou que o Ecossistema Tecnológico de combate à Covid-19 no RN é uma ferramenta pública que guiou, de forma transparente, a tomada de decisão do poder executivo no estado e nos municípios, bem como orientou decisões e recomendações dos demais poderes, como judiciário e ministérios públicos, para diferentes setores relacionados à epidemia. A maior evidência desse processo está na utilização dos relatórios técnicos produzidos pelo Ecossistema como subsídio de recomendações dos ministérios públicos, nas portarias estaduais e nos decretos do governo para a retomada gradual das atividades econômicas do estado e também das atividades escolares.

A transdisciplinaridade, própria desse Ecossistema, induziu esse dispositivo a ultrapassar sua dimensão tecnológica. Ele atuou como instrumento de articulação e reuniu sinergias para o processo decisório no campo da gestão, do trabalho em saúde, da articulação entre atores sociais, da participação social e da cooperação técnica. Além disso, a utilização da tecnologia comprovou a importância de intervenções de saúde digital para o avanço da resposta às emergências de 
saúde pública, principalmente no que concerne ao acesso oportuno da população à informação e a serviços de saúde de qualidade.

No campo da informação e da comunicação em saúde, sabe-se que "em um contexto de dúvidas, incertezas e ansiedades exponencialmente crescentes, conjugadas a disputas de narrativas que conduzem ao desgoverno e à vacância de referências centrais, o problema do controle epidêmico das doenças e das fake news é ampliado" ${ }^{51}$. Assim, a produção de informações de qualidade e a criação de estratégias de disseminação de conteúdos validados cientificamente, em linguagem acessível aos formadores de opinião e, principalmente à população em geral, foram movimentos importantes promovidos pelo Ecossistema a fim de minar a ação danosa da desinformação. $\mathrm{Ou}$ seja, ele associou inovação tecnológica e processos de comunicação e informação a serviço do controle da pandemia e da infodemia em nível local, com repercussão nacional e internacional.

Crises sanitárias, como a pandemia da Covid-19, representam um teste de resiliência para os sistemas de saúde, porque é capaz de tensionar desde as estruturas dos serviços ${ }^{52}$ (no quesito provimento e distribuição de insumos estratégicos e leitos hospitalares) até a capacidade de diálogo e pactuação entre os entes governamentais, incluindo o setor privado. Os estudos e projeções realizados no início da pandemia no Brasil, principalmente sobre a capacidade instalada no SUS, eram bastante pessimistas para um estado como o RN. No entanto, a utilização do Ecossistema demonstrou o potencial das tecnologias de saúde digital para a tomada de decisão, e de reversão de cenários da resposta à epidemia no estado. Exemplos disso foram a expansão do número de leitos Covid-19 e o aumento da frota de transporte sanitário. O Ecossistema promoveu um exercício de responsividade e de resiliência aos tensionamentos da pandemia no RN, a partir da mobilização de recursos diferenciados e da promoção de elasticidade nos comportamentos institucionais. Esses conceitos são reforçados nos estudos de Barlach et al. ${ }^{53}$, Massuda et al. ${ }^{54}$, Nuzzo et al. ${ }^{55}$ e Ammar et al. ${ }^{56}$ sobre resiliência de sistemas de saúde.

No campo da inovação em saúde, o Ecossistema permitiu ao poder público o desenvolvimento de análises e tomadas de decisões a partir de uma visão integrada entre a vigilância e a atenção em saúde, aspectos, muitas vezes, dicotômicos no Brasil $^{57}$, portanto, foi um avanço bastante desafiador. Ademais, a visão global e informatizada das áreas de vigilância e atenção no Ecossistema possibilitou a integralidade das decisões com a participação de representantes das diferentes áreas técnicas. Todos esses olhares estão apoiados nas mesmas ferramentas tecnológicas. Essa possibilidade articulou o diálogo, ainda que não isento de conflitos, entre os atores envolvidos, e induziu à qualificação das decisões na resposta à emergência de saúde pública.

Pode-se afirmar ainda que as tecnologias desenvolvidas e aplicadas no Ecossistema formaram uma cadeia de valor em saúde, que se constituiu de produtos e processos para o RN e para todas as instituições envolvidas. Para além da ferramenta tecnológica em si, observou-se que foram estabelecidas em torno dela relações de cooperação entre os atores institucionais para o processo decisório: um verdadeiro "motor" de promoção da equidade, da justiça social e da democratização do acesso aos serviços de saúde. Tornaram-se, portanto, relações de cooperação indutoras da política pública de resposta à pandemia no estado. Esse elemento é de grande relevância para futuras análises sobre o que vem sendo chamado no Brasil de "legado pós-pandemia".

A cobertura e a intensidade do uso das tecnologias em saúde pelos países indicam que a capacidade industrial, o volume de riqueza, a adaptabilidade social e a capacidade de gestão política são os ativos mais importantes a serem mobilizados diante de choques globais de múltiplas dimensões"2,58. Em ESPII, pode-se inferir que esses ativos estariam implícitos no maior ou menor potencial dos sistemas de saúde tanto de responder às exigências dos termos do RSI $(2005)^{2}$ como de mobilizar os recursos necessários para esse $\mathrm{fim}^{3}$.

Países, estados, municípios e organizações que tiveram capacidade de mobilizar recursos humanos, tecnológicos, biológicos articulando-os em prol de uma mesma causa, tendem a enfrentar com mais eficiência e sucesso a doença. Desse modo, o estudo apontou que soluções tecnológicas que ajudem a fazer a leitura de cenário funcionam na adversidade num duplo efeito: 1) como pronta resposta ao problema em questão; $\mathrm{e}$ 2) na renovação das competências e habilidades que são necessárias ao desenvolvimento dos indivíduos, fator este que proporciona um novo fôlego e uma motivação para o enfrentamento diário das atividades do sistema de saúde que são mais duras diante da crise.

A pandemia mostrou ao mundo que a disponibilidade de soluções digitais na saúde pode estar inversamente relacionada às reais necessidades de saúde das populações, talvez, por isso, 
o vírus tenha causado tantos danos à saúde global. Mesmo nos países mais ricos, onde há o uso extensivo de tecnologias, o vírus não foi contido de forma "orgânica", aspecto agravado nos países mais pobres, onde existe, inclusive, a carência de medicamentos e dispositivos mais básicos. Dessa forma, "é necessário um esforço global combinado para encorajar o desenvolvimento e o uso de tecnologias de saúde que possam beneficiar as pessoas mais pobres do mundo" ${ }^{58}$.

Alinhado ao conceito de democratização do acesso aos serviços de saúde e da promoção da equidade e da justiça social, o Ecossistema Tecnológico de combate à Covid-19 "iluminou” o RN nas tomadas de decisões. Ele evitou que o estado fosse guiado em meio a um "voo cego", o que permitiu ampliar de forma racionalizada e qualificada a atenção à população. Isso ocorreu de modo integrado a um modelo de vigilância em saúde, ordenado por dados e informações transparentes para toda a sociedade norte-rio-grandense, o que favoreceu também o controle social.

$\mathrm{Na}$ dimensão da democratização do acesso e da produção de novos conhecimentos, o Ecossistema Tecnológico de combate à Covid-19 disponibiliza um conjunto significativo de áreas de dados abertos. Esses dados possibilitam mais transparência para a sociedade e servem de base para a comunidade científica como uma valiosa fonte de pesquisa ${ }^{59-64}$.

Por fim, considera-se que "a tecnologia do homem é o que ele tem de mais humano"16. Assim, a tecnologia deve estar a serviço da humanidade, principalmente num aspecto tão importante e vital para os dias atuais como o enfrentamento de pandemias e o fortalecimento dos sistemas de saúde para uma responsividade resiliente, ágil, ética e transparente. 


\section{Colaboradores}

RAM Valentim e LR Cortez conceberam, orientaram e fizeram a gestão do desenvolvimento do projeto de pesquisa; articularam e organizaram as cooperações técnicas para o desenvolvimento, implantação e execução do projeto; definiram e analisaram a metodologia do projeto; realizaram a exploração e análise dos dados, a elaboração e interpretação dos resultados e a discussão; revisaram criticamente o manuscrito e colaboraram com todo processo de desenvolvimento do artigo; leram, contribuíram e aprovaram o manuscrito final. TS Lima definiu e analisou a metodologia do projeto; realizou a exploração e análise dos dados, a elaboração e interpretação dos resultados e a discussão; revisou criticamente o manuscrito e colaborou com todo processo de desenvolvimento do artigo; leu, contribuiu e aprovou o manuscrito final. DMS Barros participou da definição da metodologia do projeto; realizou a exploração e análise dos dados, a elaboração e interpretação dos resultados e a discussão; revisou criticamente o manuscrito e colaborou com todo processo de desenvolvimento do artigo; leu, contribuiu e aprovou o manuscrito final. RD Silva participou do desenvolvimento do projeto e realizou a exploração e análise dos dados; revisou criticamente o manuscrito e colaborou parcialmente com o processo de desenvolvimento do artigo; leu, contribuiu e aprovou o manuscrito final. JC Paiva concebeu, orientou e fez a gestão do desenvolvimento do projeto de pesquisa; colaborou parcialmente com o processo de desenvolvimento do artigo; leu, contribuiu e aprovou o manuscrito final. KD Coutinho orientou e fez a gestão parcial do desenvolvimento do projeto de pesquisa; colaborou parcialmente com o processo de desenvolvimento do artigo; leu, contribuiu e aprovou o manuscrito final. PSG Morais participou do desenvolvimento do projeto e realizou a exploração e análise dos dados; revisou criticamente o manuscrito e colaborou parcialmente com o processo de desenvolvimento do artigo; leu, contribuiu e aprovou o manuscrito final; o artigo faz parte de sua pesquisa de doutorado. JS Lacerda revisou criticamente o manuscrito e colaborou parcialmente com o processo de desenvolvimento do artigo; leu, contribuiu e aprovou o manuscrito final. FR André revisou o manuscrito e colaborou parcialmente com o processo de desenvolvimento do artigo; leu, contribuiu e aprovou o manuscrito final.

\section{Referências}

1. Epidemiology Working Group for NCIP Epidemic Response. The epidemiological characteristics of an outbreak of 2019 novel coronavirus diseases (COVID-19) in China. Zhonghua Liu Xing Bing Xue Za Zhi 2020; 41(2): 145-151.

2. World Health Organization (WHO). Recommendations on digital interventions for health system strengthening. Guideline. Geneva: WHO; 2019.

3. World Health Organization (WHO). International health regulations-2005. Geneva: WHO; 2009.

4. Agência Nacional de Vigilância Sanitária (Anvisa). Regulamento Sanitário Internacional RSI - 2005. Brasília: Anvisa; 2009.

5. Brasil. Decreto $\mathrm{n}^{\circ} 10.212$, de 30 de janeiro de 2020 . Promulga o texto revisado do Regulamento Sanitário Internacional, acordado na 58 a Assembleia Geral da Organização Mundial de Saúde, em 23 de maio de 2005. Diário Oficial da União 2020; 30 jan.

6. Buss PM, Alcázar S, Galvão LA. Pandemia pela Covid-19 e multilateralismo: reflexões a meio do caminho. Estud Av 2020, 34(99):45-64.

7. Lima NT, Buss PM, Paes-Sousa R. A pandemia de COVID-19: uma crise sanitária e humanitária. Cad Saude Publica 2020; 36(7):1-4.

8. Brasil. Ministério da Saúde (MS). Política Nacional de Informação e Informática em Saúde (PNIIS). Brasília: MS; 2016.

9. Rio Grande do Norte. Decreto no 29.541, de 20 de março de 2020. Define medidas restritivas temporárias adicionais para o enfrentamento da Emergência de Saúde Pública de Importância Internacional decorrente do novo coronavírus (COVID-19). Diário Oficial do Estado 2020; 20 mar.

10. Tripp D. Pesquisa-ação: uma introdução metodológica. Educ Pesquisa 2005; 31(3):443-466.

11. Rani SBASU. A detailed study of Software Development Life Cycle (SDLC) models. Int J Eng Computer Sci 2017; 6:7.

12. George MS, Richard LH. A systems engineering perspective on the human-centered design of health information systems. J Biomed Inform 2005; 38(1):61-74.

13. Sousa TL. Uso do Scrum na Contratação de Fábrica de Software: Uma Pesquisa-Ação em um Órgão Público Federal Brasileiro [monografia]. Brasília: Universidade de Brasília; 2014.

14. Nidagundi P, Novickis L. Introducing lean canvas model adaptation in the Scrum Software Testing. Procedia Computer Science 2017; 104:97-103.

15. Schwaber K. Scrum development process. In: Business object design and implementation. Londres: Springer; 1997. p. 117-134.

16. McLuhan M. McLuhan por McLuhan: conferências e entrevistas. Rio de Janeiro: Ediouro; 2005.

17. Goldenberg M. A arte de pesquisar: como fazer pesquisa qualitativa em Ciências Sociais. $8^{\text {a }}$ ed. Rio de Janeiro: Editora Record; 2004.

18. Yin RK. Estudo de caso: planejamento e métodos. Porto Alegre: Bookman; 2010. 
19. Kingdon JW. Agendas, alternatives, and public policies. New York: HarperCollins College Publishers; 1995.

20. Laboratório de Inovação Tecnológica em Saúde (LAIS), Universidade Federal do Rio Grande do Norte (UFRN). Plataforma Coronavírus RN. Versão 1.0 [programa de computador]. Natal: LAIS, UFRN; 2020 [acessado 2020 ago 01]. Disponível em: https://covid. lais.ufrn.br.

21. Rio Grande do Norte. Secretaria de Estado de Saúde Pública. Plano de Contingência Estadual para Infecção Humana pelo novo Coronavírus [Internet]. 2020 [acessado 2020 ago 08]. Disponível em: https://www. saude.gov.br/images/pdf/2020/fevereiro/13/PLANO-DE-CONTINGENCIA-novo-coronavirus-RIOGRANDE-DO-NORTE-EM-REVIS--O.pdf.

22. Brasil. Lei no 13.979, de 06 de fevereiro de 2020. Dispõe sobre as medidas para enfrentamento da emergência de saúde pública de importância internacional decorrente do coronavírus responsável pelo surto de 2019. Presidência da República, Secretaria-Geral, Subchefia para Assuntos Jurídicos. Diário Oficial da União 2020; $06 \mathrm{fev}$.

23. Brasil. Portaria no 356, de 11 de março de 2020. Dispõe sobre a regulamentação e operacionalização do disposto na Lei $\mathrm{n}^{\circ} 13.979$, de 6 de fevereiro de 2020, que estabelece as medidas para enfrentamento da emergência de saúde pública de importância internacional decorrente do coronavírus (COVID-19). Diário Oficial da União 2020; 11 mar.

24. Rio Grande do Norte. Secretaria de Estado de Saúde Pública. Governo do Rio Grande do Norte. Recomendação $n^{\circ}$ 04/2020 [Internet]. 2020 [acessado 2020 ago 01]. Disponível em: https://covid.lais.ufrn. br/publicacoes/recomendacao_comite_n04_2020. pdf.

25. World Health Organization (WHO). Marco para um Centro de Operações de Emergências. Framework de 2015. Genebra: WHO; 2017.

26. World Health Organization (WHO). COVID-19 Strategy Update. Genebra: WHO; 2020

27. Organização Pan-Americana de Saúde (OPAS). Departamento de Evidência e Inteligência para Ação em Saúde. Entenda a Infodemia e a desinformação na luta contra a COVID-19 [Internet]. [acessado 2020 ago 10]. Disponível em: https://iris.paho.org/bitstream/ handle/10665.2/52054/Factsheet-Infodemic_por.pdf? sequence $=14$.

28. Gianicolo E, Riccetti N, Blettner M, Karch A. Epidemiological Measures in the Context of the COVID-19 Pandemic. Dtsch Arztebl Int 2020; 117(19):336-342.

29. Raju V, Mohd J, Ibrahim HK, Abid H. Artificial Intelligence (AI) applications for COVID-19 pandemic. Diabetes Metab Syndr 2020; 14(4):337-339.

30. Hart OE, Halden RU. Computational analysis of SARS-CoV-2/COVID-19 surveillance by wastewater-based epidemiology locally and globally: Feasibility, economy, opportunities and challenges. Sci Total Environ 2020; 730:138875.

31. Foddai A, Lindberg A, Lubroth J, Ellis-Iversen J. Surveillance to improve evidence for community control decisions during the COVID-19 pandemic. One Health 2020; 9:100130.
32. Yuan J, Li M, Lv G, Lu ZK. Monitoring transmissibility and mortality of COVID-19 in Europe. Int J Infect Dis 2020; 95:311-315.

33. Bokolo AJ. Exploring the adoption of telemedicine and virtual software for care of outpatients during and after COVID-19 pandemic. Ir J Med Sci 2020; 190(1):1-10.

34. Gozes O, Frid-Adar M, Greenspan H, Browning PD, Zhang H, Ji W, Bernheim A, Siegel E. Rapid AI development cycle for the coronavirus (covid-19) pandemic: initial results for automated detection \& patient monitoring using deep learning CT image analysis. arXiv 2020 [preprint]. Disponível em: https:// ui.adsabs.harvard.edu/abs/2020arXiv200305037G.

35. Kumar A, Gupta PK, Srivastava A. A review of modern technologies for tackling COVID-19 pandemic. Diabetes Metab Syndr 2020; 14(4):569-573.

36. Kittel B, Kritzinger S, Boomgaarden H, Prainsack B, Eberl JM, Kalleitner F, Schlogl L. The Austrian Corona Panel Project: monitoring individual and societal dynamics amidst the COVID-19 crisis. Eur Polit Sci 2020; $1-27$

37. Javaid M, Haleem A, Vaishya R, Bahl S, Suman R, Vaish A. Industry 4.0 technologies and their applications in fighting COVID-19 pandemic. Diabetes Metab Syndr 2020; 14(4):419-422.

38. Wiener N. Cibernética e sociedade: $O$ uso humano de seres humanos. São Paulo: Cultrix; 1968.

39. Agora RN. Fátima cancela campanha publicitária sobre coronavírus; verba era de $R \$ 3$ milhões [Internet]. 2020 [acessado 2020 abr 4]. Disponível em: https://agorarn. com.br/politica/fatima-cancela-campanha-publicitaria-sobre-coronavirus-verba-era-de-r-3-milhoes/.

40. Laboratório de Inovação Tecnológica em Saúde (LAIS), Universidade Federal do Rio Grande do Norte (UFRN). Plataforma RegulaRN. Sala de Situação Versão 1.0 [programa de computador]. Natal: LAIS, UFRN; 2020 [acessado 2020 ago 01]. Disponível em: https://regulacao.lais.ufrn.br/sala-situacao/sala_publica/.

41. Brasil. Ministério da Saúde (MS). Política Nacional de Informação e Informática em Saúde [Internet]. Brasília: MS; 2016 [acessado 2020 ago 08]. Disponível em: https://www.conasems.org.br/wp-content/uploads /2019/02/politica_nacional_infor_informatica_saude_2016.pdf.

42. Governo Federal. Coronavírus Brasil. Painel Coronavírus [Internet]. [acessado 2020 ago 01]. Disponível em: https://covid.saude.gov.br/.

43. Transparência COVID-19 2.0. Dados abertos podem salvar vidas [Internet]. [acessado 2020 ago 01]. Disponível em: https://transparenciacovid19.ok.org.br/.

44. Laboratório de Inovação Tecnológica em Saúde (LAIS). Universidade Federal do Rio Grande do Norte (UFRN). Secretaria de Saúde do Município do Natal (SMS/Natal-RN). Plataforma Salus - Dados abertos do Salus. Versão 1.0 [programa de computador]. Natal UFRN, LAIS, SMS/Natal-RN; 2020 [acessado 2020 ago 01]. Disponível em: https://salus.lais.ufrn.br/indicadores/painel_publico. 
45. Globo G1 RN. Idosos poderão ser vacinados contra a gripe dentro de condomínios em Natal: Cerca de 71 mil idosos já foram vacinados na capital potiguar [Internet]. Natal; 2020 [acessado 2020 mar 27]. Disponível em: https://g1.globo.com/rn/rio-grande-do-norte/noticia/2020/03/27/idosos-poderao-ser-vacinados- contra-a-gripe-dentro-de-condominios-em-natal. ghtml.

46. Agora RN. Idosos de Natal vão poder receber a vacina da gripe nos condominios onde residem: A partir deste sábado (28) até 05 de abril, o síndico pode acessar o sistema e preencher o formulário [Internet]. Natal; 2020 [acessado 2020 mar 27]. Disponível em: https:// agorarn.com.br/geral/idosos-de-natal-vao-poder-receber-a-vacina-da-gripe-nos-condominios-onde-residem/.

47. Laboratório de Inovação Tecnológica em Saúde (LAIS). Projeto da UFRN vai ajudar na vacinação de idosos em condomínios de Natal durante a pandemia [Internet]. Natal; 2020 [acessado 2020 mar 30]. Disponível em: https://lais.huol.ufrn.br/projeto-da-ufrnvai-ajudar-vacinacao-de-idosos-em-condominiosde-natal-durante-a-pandemia.

48. Tribuna do Norte. UFRN cadastra condomínios que terão serviços de vacinação a idosos [Internet]. Natal; 2020 [acessado 2020 mar 24]. Disponível em: http:// www.tribunadonorte.com.br/noticia/ufrn-cadastracondoma-nios-que-tera-o-servia-o-de-vacinaa-a-o-a -idosos/475639.

49. Tropical. Mais de 3 mil idosos são vacinados contra gripe em condomínios de Natal [Internet]. Natal; 2020 [acessado 2020 abr 24]. Disponível em: https://www. portaldatropical.com.br/news/mais-de-3-mil-idosossao-vacinados-contra-gripe-em-condominios-de-natal.

50. Laboratório de Inovação Tecnológica em Saúde (LAIS). Orienta Corona RN possibilita fácil acesso à informação sobre a Covid-19 [Internet]. Natal; 2020 [acessado 2020 abr 24]. Disponível em: https://lais. huol.ufrn.br/orienta-corona-rn-possibilita-facil-acesso-a-informacao-sobre-a-covid-19.

51. Vasconcellos-Silva PR, Castiel LD. COVID-19, às fake news e o sono da razão comunicativa gerando monstros: a narrativa dos riscos e os riscos das narrativas. Cad Saude Publica 2020; 36(7):e00101920.

52. Rache B, Rocha R, Nunes L, Spinola P, Malik AM, Massuda A. Necessidades de infraestrutura do SUS em preparo à COVID-19: leitos de UTI, respiradores e ocupação hospitalar. IEPS 2020; 3:1-5. [Nota Técnica].

53. Barlach L, Limongi-França AC, Malvezzi S. O conceito de resiliência aplicado ao trabalho nas organizações. Interam J Psychol 2018; 42(1):101-112.

54. Massuda A, Hone T, Leles FAG, de Castro MC, Atun R. The Brazilian health system at crossroads: progress, crisis and resilience. BMJ Global Health 2018; 3:e000829.

55. Nuzzo JB, Meyer D, Snyder M, Ravi SJ, Lapascu A, Souleles J, Bishai, D. What makes health systems resilient against infectious disease outbreaks and natural hazards? Results from a scoping review. BMC Public Health 2019; 19(1):1310.
56. Ammar W, Kdouh O, Hammoud R, Hamadeh R, Harb H, Ammar Z, Zalloua PA. Health system resilience: Lebanon and the Syrian refugee crisis. J Global Health 2016; 6:2.

57. Howitt P, Darzi A, Yang GZ, Ashrafian H, Atun R, Barlow J, Cooke GS. Technologies for global health. Lancet 2012; 380(9840):507-535.

58. Coelho Neto GC. Integração entre Sistemas de Informação em Saúde: o caso do e-SUS Atenção Básica [dissertação]. São Paulo: Universidade Federal de São Paulo; 2019.

59. Valentim RAM, Coutinho KD, Morais AHF, Lima TS, Guimarães MCS, Silva Neto JHV. Conectividade e digitalização no contexto da saúde global: um olhar para o futuro inspirado na saúde 4.0. In: Departamento do Complexo Industrial e Inovação em Saúde, Secretaria de Ciência, Tecnologia e Insumos Estratégicos, Ministério da Saúde (MS), organizador. Avanços, desafios e oportunidades no Complexo Industrial da Saúde em serviços tecnológicos. Brasília: MS; 2018. p. 254-273.

60. Plataforma Coronavírus RN. Dados abertos epidemiológicos e laboratoriais [Internet]. Natal: UFRN; 2020 [acessado 2020 out 14]. Disponível em: https://covid. lais.ufrn.br/\#dados.

61. Plataforma Coronavírus RN. Documentos do repositório do LAIS/UFRN durante a covid-19 [Internet]. Natal: UFRN; 2020 [acessado 2020 out 14]. Disponível em: https://covid.lais.ufrn.br/\#documentos

62. Plataforma Coronavírus RN. Dados abertos capacitados em covid-19 [Internet]. Natal: UFRN; 2020 [acessado 2020 out 14]. Disponível em: https://covid.lais. ufrn.br/\#capacitados-em-covid19

63. Plataforma RegulaRN. Dados abertos regulação de leitos covid-19 no RN [Internet]. Natal: UFRN; 2020 [acessado 2020 out 14]. Disponível em: https://regulacao.lais.ufrn.br/sala-situacao/sala_publica/.

64. Portal covid-19 RN. Documentos do Comitê Científico do RN produzidos durante a covid-19 [Internet]. 2020 [acessado 2020 out 14]. Disponível em: https://portalcovid19.saude.rn.gov.br/medidas/comite-cientifico-do-rio-grande-do-norte/.

Artigo apresentado em 13/09/2020 Aprovado em 15/01/2021

Versão final apresentada em 17/01/2021

Editores-chefes: Maria Cecília de Souza Minayo, Romeu Gomes, Antônio Augusto Moura da Silva 